\title{
Calculation and analysis of internal force of piles excavation supporting based on differential equation
}

\author{
Wei Wang \\ School of Prospecting and Surveying of Changchun Institute of Technology, Changchun, China \\ 16695496@qq.com
}

Keywords: differential equation, piles excavation supporting, calculation of internal force, Maple calculation software, correction coefficient.

Abstract. The article proposes a new method of calculating the internal force of row piles structure in excavation engineering by powerful function of solving differential equations of Maple software. this method can finally obtain the analytical function of displacement, bending moment and shear force of the structure, based on the Maple software as auxiliary tool, dividing the calculation unit of structure, establishing the differential equations and the boundary conditions of the equation set according to stress analysis and coordination deformation. It is proved that the new calculation of internal force can be applied for cantilever retaining structure, through analysis on practical engineering case and comparison with the results calculated by Lizheng software, and it finally proposes the correction coefficient of Maple calculation.

\section{Introduction}

Structures of excavation support suffer horizontal loads mainly, including water pressure, soil pressure, and ground overloads, such as additional pressures. The soils around the excavation is regarded as the load in the traditional support design, and it chooses the type of soil pressure to design according to displacement of retaining structure. With the rapid development of computer technology, some mathematical calculation methods and software is gradually applied to the analysis and calculation of excavation support structure, and gradually formed a complete set of numerical simulation analysis method. Bowles ${ }^{[1]}$ programmed to solve the finite element analysis of elastic foundation beam. Morishige ryoma ${ }^{[2]}$ simulated transformations of soil pressure on retaining walls, and proposed the calculation method that displacement makes soil pressure increasing or decreasing. Guo Yurong ${ }^{[3]}$ proposed a nonlinear model for calculating separately the soil pressure and soil resistance upon or below the excavation face. Zhao Yonglun ${ }^{[4]}$ revised the horizontal resistance coefficient in the finite element analysis method of elastic rod system. In addition, the finite element analysis method can also be used with a lot of influence factors together, and establish the constitutive relation model of soil. It is one of the widely used analytical methods at present. The internal force analysis of retaining structure is an important part in the design of excavation engineering, and the common methods are static equilibrium and elastic fulcrum. The article makes the row piles supporting structure as the research object, according to the theory of elastic foundation. It established differential equation expressions of each unit by dividing the computing unit of structure, and set the boundary conditions, then finally worked out the analytical functions of internal force of row piles structure. 


\section{The establishment of differential equation set}

\section{Division of computing units}

According to the form of supporting structure, the nature of soils behind the wall, and the nature and the layer of the soil below the excavation face, the computing unit of the excavation supporting structure is divided. Based on the elastic fulcrum method as an example, such as the use of cantilever, it is suffered only from soil pressure worked on the wall that the part above the excavation face and it can be used as one computing unit. Below the excavation face, using the Winkler foundation model to analysis, each supporting structure within each depth range can be used as one computing unit, because of the $m$ value of each soil is different. When using multi pivot point supporting forms, such as soil nailing wall or pile anchor retaining structure, each soil nailing or anchor set point can be a computing unit node above the excavation face, and it is divided according to the depth of soil below the excavation face. Computing unit division of cantilever structure as shown in Figure 1, and computing unit division of soil nailing or pile anchor supporting structure as shown in Figure 2.

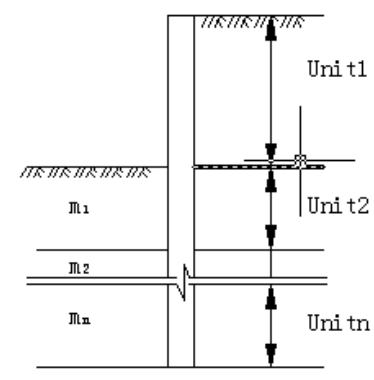

Fig.1 Cantilever computing unit division

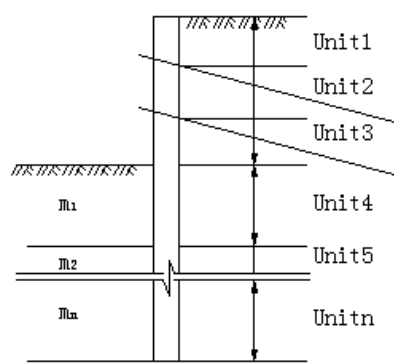

Fig.2 Fulcrum computing unit division

\section{The establishment of differential equation}

As shown in Figure 1, the supporting structure above the excavation face only suffers the soil pressure from the wall back, and the supporting structure below the excavation face establishes the equation according to the deflection differential equation of pile, in order to calculate the zero point of excavation face. The differential equation of the cantilever section is shown in Eq.1, and the differential equation of the solid segment is shown in Eq.3.

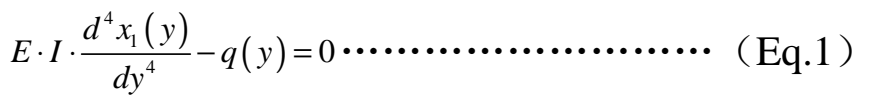

In the equation, qy is the soil pressure from wall back, and it can be calculated according to Eq.2

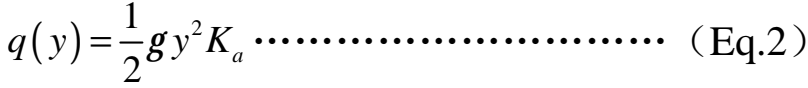

$$
\begin{aligned}
& \left\{\begin{array}{l}
E \cdot I \cdot \frac{d^{4} x_{2}(y)}{d y^{4}}+m_{1} \cdot y \cdot B_{p} \cdot x_{2}(y)=0 \\
\mathrm{M} \\
E \cdot I \cdot \frac{d^{4} x_{n}(y)}{d y^{4}}+m_{n} \cdot y \cdot B_{p} \cdot x_{n}(y)=0
\end{array}\right.
\end{aligned}
$$

Bring Eq.2 into Eq.1, and combine with Eq.3 at the meanwhile, the equation set obtained is the differential equation of the cantilever structure. As shown in Eq.4. 


$$
\left\{\begin{array}{c}
E \cdot I \cdot \frac{d^{4} x_{1}(y)}{d y^{4}}-\frac{1}{2} \gamma y^{2} K_{a}=0 \\
E \cdot I \cdot \frac{d^{4} x_{2}(y)}{d y^{4}}+m_{1} \cdot y \cdot B_{p} \cdot x_{2}(y)=0 \ldots \ldots \ldots \ldots \ldots \ldots \ldots \ldots \ldots \ldots \ldots \ldots \ldots \ldots \\
\mathrm{M} \\
E \cdot I \cdot \frac{d^{4} x_{n}(y)}{d y^{4}}+m_{n} \cdot y \cdot B_{p} \cdot x_{n}(y)=0
\end{array}\right.
$$

As shown in Figure 2, taking the pile anchor supporting structure as an example, the two fulcrums in the figure can be regarded as two horizontal forces F1 and F2, therefore, the differential equation of supporting structure above the excavation face is shown in Eq.5. The differential equation of supporting structure below the excavation face is same to the cantilever, as shown in Eq.6. The differential equations set of the whole excavation supporting structure is shown in Eq.7.

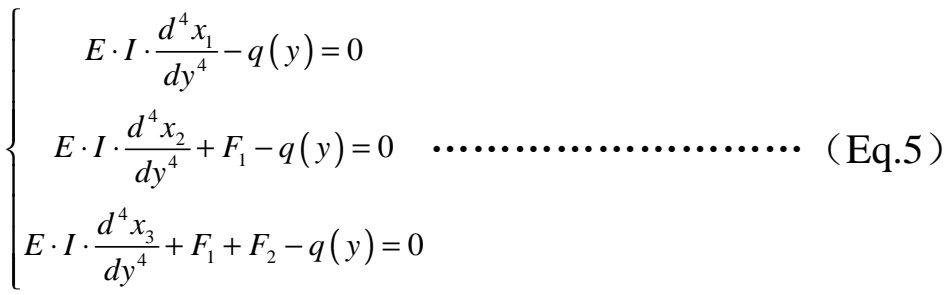

$$
\begin{aligned}
& \left\{\begin{array}{l}
E \cdot I \cdot \frac{d^{4} x_{4}(y)}{d y^{4}}+m_{1} \cdot y \cdot B_{p} \cdot x_{4}(y)=0 \\
\mathrm{M} \\
E \cdot I \cdot \frac{d^{4} x_{n}(y)}{d y^{4}}+m_{n} \cdot y \cdot B_{p} \cdot x_{n}(y)=0
\end{array}\right.
\end{aligned}
$$

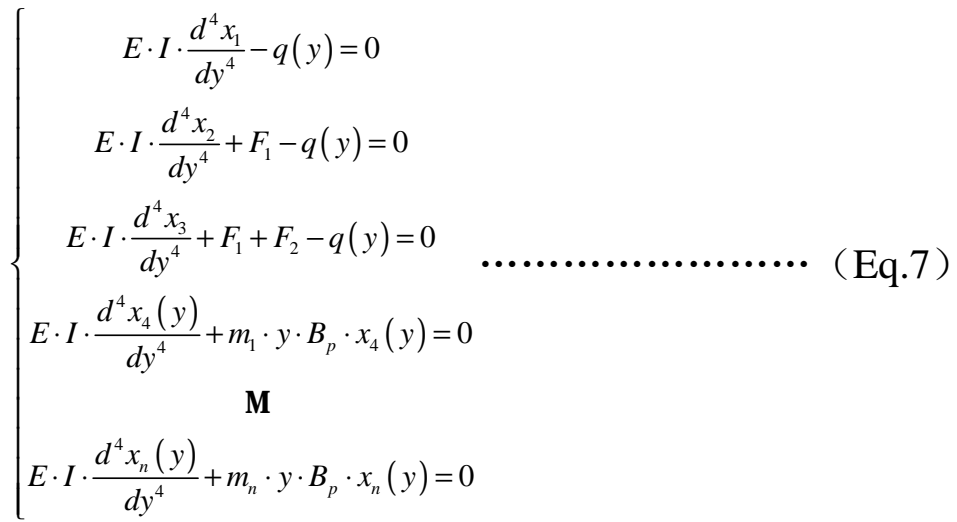

\section{Determination of boundary conditions}

The boundary conditions are identified including two aspects, the top and the bottom of the structure. The top boundary condition is usually considered at the free end, and it is related to the external load affected whether or not. If there is no external load, the shear $\mathrm{Q}$ and the bending moment $\mathrm{M}$ on the top of the supporting structure are zero, and the differential equation of the boundary condition is shown in Eq.8. If the external loads exist, the shear Q and bending moment $M$ are fixed values. In addition, it is according to deformation synergy at each unit node and the bending moment, shears upon and below is same at the node to establish the boundary condition. The differential equation of boundary condition is shown in Eq.9. The bottom boundary condition of supporting structure should be determined according to the condition of the embedded. When the bottom of the structure is not embedded into the hard soil layer, it is regarded as friction piles to calculate, and the bending moment and shear force at the bottom of the structure are both zero. The differential equation of boundary is shown in Eq.10. When the bottom of the structure is embedded 
in the hard soil or rock, it is regarded as rock embedded pile to calculate, and the horizontal displacement and the rotation angle of the structure are zero. The differential equation of boundary is shown in Eq.11.

According to the type of supporting structure, it needs to choose the corresponding differential equation to form the equation set of boundary conditions. And this equation set is the differential equation of the boundary conditions for excavation supporting structure.

$$
\begin{aligned}
& \left\{\begin{array}{l}
E \cdot I \cdot \frac{d^{3} x_{1}(0)}{d y^{3}}=C_{1} \\
E \cdot I \cdot \frac{d^{2} x_{1}(0)}{d y^{2}}=C_{2} \text { no external load, } C_{1} \text { and } C_{2} \text { are zero } \cdots \cdots \cdots(\text { Eq.8) }
\end{array}\right.
\end{aligned}
$$

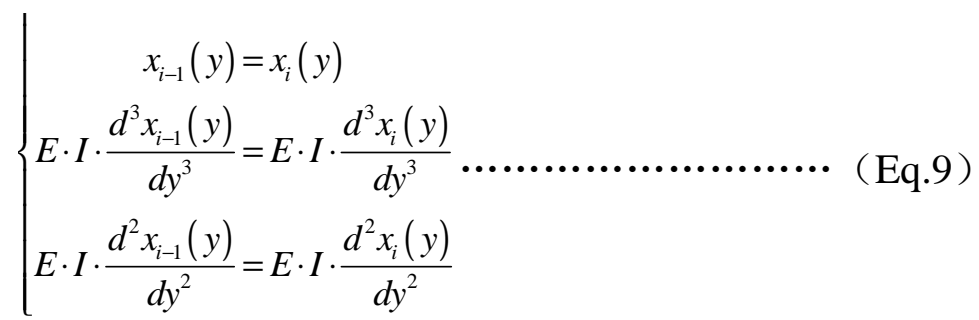

$$
\begin{aligned}
& \left\{\begin{array}{l}
E \cdot I \cdot \frac{d^{3} x_{n}(h)}{d y^{3}}=0 \\
E \cdot I \cdot \frac{d^{2} x_{n}(h)}{d y^{2}}=0
\end{array}\right.
\end{aligned}
$$

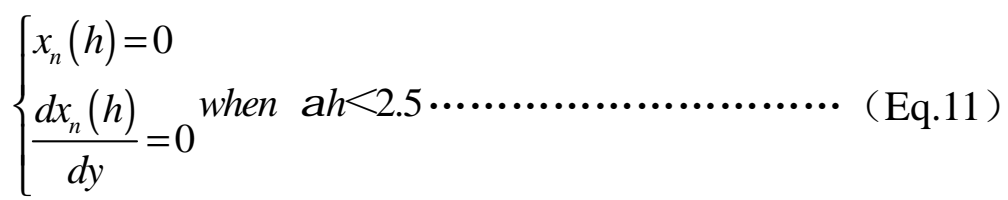

\section{Case analyses}

\section{Engineering survey}

It is a high-rise residential building engineering in Chengdu which the importance of the project level is the first class. The south, north and east of the excavation has been supported in the early. The original plan of west excavation is to use soil nailing walls and anchor together to support. Due to the inconsistent between the original data and the local stratigraphy founded in construction, and serious seepage from municipal pipelines surrounded to the excavation, there is local collapse in $\mathrm{AD}$ section of excavation. Therefore, it is going to arrange the pile supporting and the reinforced net spraying concrete sealing between piles again. Excavation depth is 9meters, embedded depth is 8 meters, and there is a strip of $20 \mathrm{kPa} / \mathrm{m}$ of the ground overload from the edge of excavation is 0.5 meters, and the width is 10 meters. The excavation is mainly composed of artificial fill, silty clay, sand, gravel, and weathered mudstone. After precipitation, the groundwater table is located 25 meters below the ground. According to different soil conditions, the west is divided into three sections, $\mathrm{AB}, \mathrm{BC}$, and $\mathrm{CD}$. The diameters of the three are all 1.2meters. The pile spacing of $\mathrm{AB}$ and $\mathrm{CD}$ section is 2 meters, and $\mathrm{BC}$ is 1.9 meters. Some part needs to add piles, the diameter of pile spacing is 3 meters, and the pull is 1.2 meters. The pile body is C30 reinforced concrete. The plan layout of excavation is as shown in Fig.3, and profile is as shown in Fig.4. According to the field survey data, the distribution of the ground surface and the physical and mechanical parameters are shown in Table 1. 


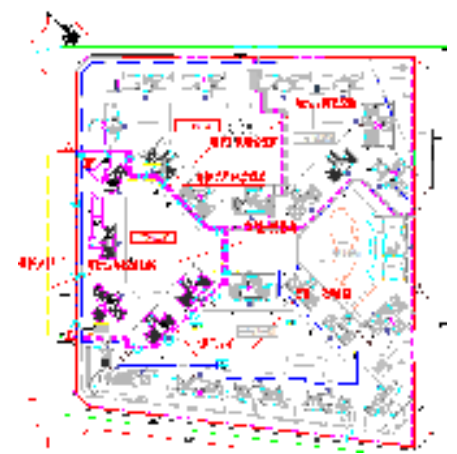

Fig.3 Layout plan of excavation

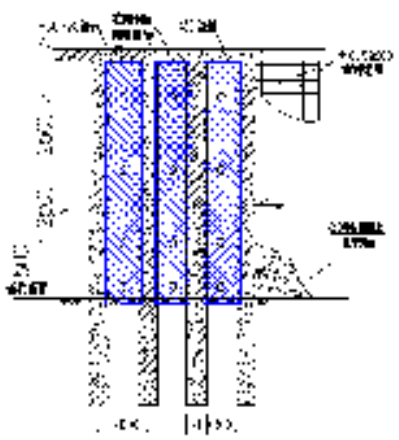

Fig.4 Excavation profile

Table 1 Summary table of soil layer distribution and physical and mechanical indexes

\begin{tabular}{|c|c|c|c|c|c|c|c|}
\hline Name of soil layer & $\begin{array}{r}\text { Thick } \\
\text { layer } \\
(\mathrm{m})\end{array}$ & $\begin{array}{c}\text { Bulk density } \\
\gamma\left(\mathrm{kN} / \mathrm{m}^{3}\right)\end{array}$ & $\begin{array}{c}\text { Compression } \\
\text { modulus } \\
\mathrm{E}_{\mathrm{s}}(\mathrm{MPa})\end{array}$ & $\begin{array}{c}\text { Deformation } \\
\text { modulus } \\
\mathrm{E}_{0}(\mathrm{MPa})\end{array}$ & $\begin{array}{c}\text { Cohesion } \\
\mathrm{C}(\mathrm{kPa})\end{array}$ & $\begin{array}{c}\text { Internal } \\
\text { friction } \\
\text { angle } \\
\varphi\left({ }^{\circ}\right)\end{array}$ & $\begin{array}{l}\text { Ratio coefficient } \\
\qquad \mathrm{m}\left(\mathrm{kN} / \mathrm{m}^{4}\right)\end{array}$ \\
\hline Miscellaneous fill & 2.50 & 18.5 & 4 & / & 10 & 8 & 1500 \\
\hline Clay & 3.80 & 19.6 & 8 & & 37 & 15 & 5000 \\
\hline Silty clay & 1.20 & 19.8 & 7 & l & 24 & 18 & 5000 \\
\hline Fine sand & 1.50 & 17.0 & 6 & l & I & 21 & 7000 \\
\hline Loose pebble & 0.60 & 21.0 & 18 & 16 & I & 30 & 15000 \\
\hline Slightly dense pebble & 1.00 & 22.0 & 25.0 & 22.0 & 3 & 35 & 20000 \\
\hline Medium dense pebble & 1.70 & 23.0 & 40.0 & 32.0 & 5 & 40 & 28000 \\
\hline Compacted gravel & 1.40 & 24.0 & 52.7 & 39.0 & 5 & 45 & 45000 \\
\hline $\begin{array}{l}\text { Medium weathered } \\
\text { mudstone }\end{array}$ & 10.00 & 24.0 & I & I & 200 & 38 & 38000 \\
\hline
\end{tabular}

\section{Calculation result analysis}

By the algebraic calculation system of Maple to solve, it can calculate the equation of the displacement, bending moment and shear force that change along with the depth $\mathrm{Z}$, and obtain the curve drawing, as shown from Fig.5 to Fig.7.

As shown in figures, the lateral displacement of piles changed with depth is more and more small. The maximum displacement at the top of the pile is $33.2 \mathrm{~mm}$. The maximum moment of piles is $1638.7 \mathrm{kN} \cdot \mathrm{m}$, and it is located 1.9 meters below the excavation face. The maximum shear force is $552.8 \mathrm{kN}$ which is 4.6 meters below the excavation face. All values of each node calculated by Maple are summarized in Table 2 .

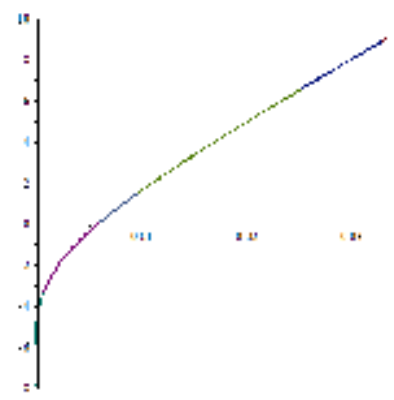

Fig.5 displacement curve of row piles

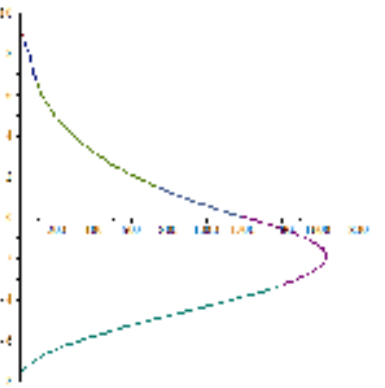


Fig.6 Bending moment curve of row piles

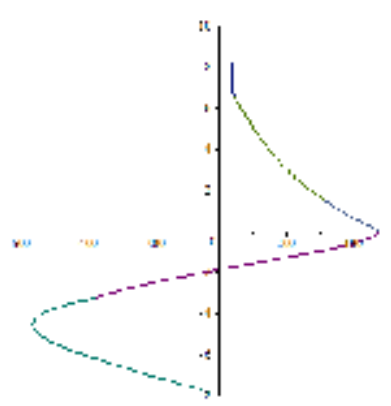

Fig.7 Shear force curve of row piles

Table 2 Results calculated by Maple

\begin{tabular}{|c|c|c|c|}
\hline & $\begin{array}{c}\text { Displacement } \\
(\mathrm{mm})\end{array}$ & $\begin{array}{c}\text { Bending moment } \\
(\mathrm{kN} \cdot \mathrm{m})\end{array}$ & $\begin{array}{c}\text { Shear force } \\
(\mathrm{kN})\end{array}$ \\
\hline-9.0 & 33.2 & 0 & 0 \\
\hline-8.85 & 32.8 & 24.56 & 18.0 \\
\hline-6.5 & 25.0 & 99.69 & 45.1 \\
\hline-1.5 & 9.7 & 727.53 & 313.0 \\
\hline 0 & 5.8 & 1192.60 & 477.7 \\
\hline 1.9 & 2.2 & 1638.70 & 0.3 \\
\hline 3.3 & 0.7 & 1414.97 & -369.1 \\
\hline 4.6 & 0 & 902.32 & -552.8 \\
\hline 8.0 & -0.2 & 0 & 0 \\
\hline
\end{tabular}

\section{Compared with the results calculated by Lizheng software}

Design the structure of row piles by Lizheng software, and summarize the results in the Table 3. Compare the results calculated by Maple with that calculated by Lizheng, and the contrast diagrams of displacement, bending moment and shear force are shown from Fig.8 to Fig.10.

Table 3 Results calculated by Lizheng

\begin{tabular}{|c|c|c|c|}
\hline & $\begin{array}{c}\text { Displacement } \\
(\mathrm{mm})\end{array}$ & $\begin{array}{c}\text { Bending moment } \\
(\mathrm{kN} \cdot \mathrm{m})\end{array}$ & $\begin{array}{c}\text { Shear force } \\
(\mathrm{kN})\end{array}$ \\
\hline$\cdot 9.0$ & 30.9 & 0 & 0 \\
\hline$\cdot 8.85$ & 29.8 & 20.1 & 15.1 \\
\hline$\cdot 6.5$ & 22.1 & 95.6 & 40.3 \\
\hline$\cdot 1.5$ & 8.5 & 705.3 & 301.8 \\
\hline 0 & 5.1 & 1176.3 & 460.9 \\
\hline 1.9 & 1.9 & 1613.9 & 0 \\
\hline 3.3 & 0.2 & 1403.9 & -355.8 \\
\hline 4.6 & 0 & 885.3 & -547.9 \\
\hline 8.0 & 0 & 0 & 0 \\
\hline
\end{tabular}

displacement curve
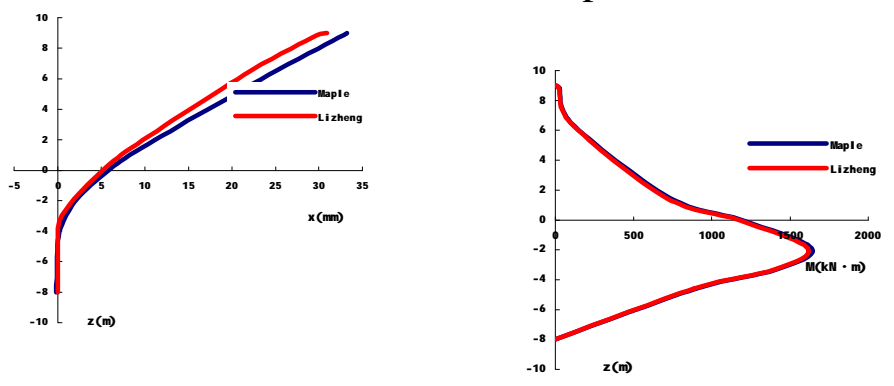

Fig.9 Contrast diagram of bending moment curve

Fig.8 Contrast diagram of 


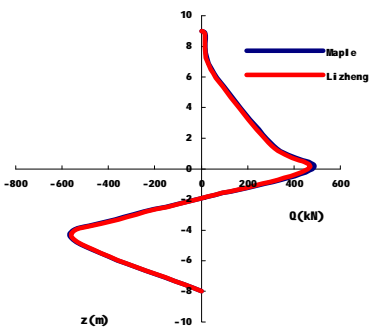

Fig.10 Contrast diagram

of shear force curve

By comparison, it is nearly the same that the trend of curves calculated by the two calculations. From the numerical point of view, results of Maple are a little larger than that of Lizheng. The position of the maximum bending moment and the zero position of the horizontal force are almost the same, and the displacements of the top is only $3 \mathrm{~mm}$ left between two calculations, which can be ignored in the actual engineering. The reinforcement of the structure is more favorable for the stability according to the maximum bending moment by Maple.

\section{Compared with the actual monitoring data}

Make a comparison with data obtained by actual monitoring, and the contrast diagrams are shown in Fig.11 and Fig.12. Results calculated by Maple are larger than the actual monitoring data, and the ratio between the two points is around 0.85 . It can obtain the actual displacement of structure by multiplying 0.85 on the value calculated by Maple. 0.85 can be regarded as the correction coefficient of Maple calculation.

\section{Conclusions}

The article proposes a new calculation of internal force of row piles structure in excavation engineering, and this method can finally obtain the analytical function of internal force of the structure, based on the Maple software as auxiliary tool, dividing the calculation unit of structure, establishing the differential equations and the boundary conditions of the equation set according to stress analysis and coordination deformation. Through the analysis on practical engineering case, comparing with the results calculated by Lizheng, there are conclusions following:

(1) The calculation results of Maple are a little larger, but the changes trends of displacement, bending moment and shear force are basically the same.

(2) Compared with the actual monitoring data, there is a correction coefficient of Maple calculation, and the value is 0.85 .

(3) The calculation based on differential equation can be applied to internal force analysis of the cantilever excavation supporting structure, and the result is accurate and reliable.

\section{References}

[1] J. E. Bowles, T Nianci translated, Foundation engineering and analysis(3rd edition) published by China Architecture and Building Press in 1987

[2] G Xiaonan, Construction and Design Manual of Deep Excavation engineering published by China Architecture and Building Press in 1998

[3] G Yurong, Study on Design Method and Computer Aided Design of Retaining Structures of Foundation pit, the degree thesis of Hunan University in 1999

[4] ZH Yonglun, An Modification Procedure on Elastic Bar System FEM Concerning Constructing 
Factors published in Soil Eng. and Foundation, Vol.13 No.3, Sept.1999 